Low bi rth wei ght of Vi et namese i nf ant s is $r$ el at ed to thei $r$ mother' $s$ di oxi $n$ and gl ucocort i coi d I evel s

\begin{tabular}{|l|l|}
\hline 著者 & $\begin{array}{l}\text { Tung Dao Van, Ki do Ter uhi ko, Honma Sei j i r o, } \\
\text { Nanh Ho Dung, Nhu Dang Duc, Okanot o Ri e, } \\
\text { Nar uzeni Shoko, N shi j o Muneko, Nakagawa } \\
\text { H deaki, Ngoc Pham Thi en, Toan Ngo Van, Hung } \\
\text { Nguyen Ngoc, M nh Nuyen Hung, Son Le Ke }\end{array}$ \\
\hline $\begin{array}{l}\text { j our nal or } \\
\text { publ i cat i on t i tl e }\end{array}$ & Envi r onnent al Sci ence and Pol I ut i on Resear ch \\
\hline vol une & 23 \\
\hline number & 11 \\
\hline page r ange & $10922-10929$ \\
\hline year & $2016-06-01$ \\
\hline URL & ht t p: //hdl . handl e. net /2297/44883 \\
\hline
\end{tabular}




\title{
Low birth weight of Vietnamese infants is related to their mother's dioxin and glucocorticoid levels
}

Dao Van Tung ${ }^{1,2}$, Teruhiko Kido ${ }^{3 *}$, Seijiro Honma ${ }^{3}$,Ho Dung Manh ${ }^{3,4}$, Dang Duc Nhu ${ }^{3,5}$, Rie Okamoto ${ }^{3}$, Shoko Maruzeni ${ }^{1,6}$, Muneko Nishijo ${ }^{6}$, Hideaki Nakagawa ${ }^{6}$, Pham Thien Ngoc ${ }^{1}$, Ngo Van Toan ${ }^{1}$, Nguyen Ngoc Hung ${ }^{1}$, Nguyen Hung Minh ${ }^{7}$, Le Ke Son ${ }^{7}$

${ }^{1}$ Hanoi Medical University, No. 1 Ton That Tung, Dong Da, Hanoi, Vietnam

${ }^{2}$ Viettiep Hospital, No. 1 Nha Thuong, Le Chan, Hai Phong, Vietnam

${ }^{3}$ Faculty of Health Sciences, Institute of Medical Pharmaceutical and Health Sciences, Kanazawa University, 5-11-80 Kodatsuno, Kanazawa, Japan 920-0942

${ }^{4}$ Faculty of Pharmacy, Lac Hong University, Bien Hoa, Vietnam

${ }^{5}$ School of Medicine and Pharmacy, Vietnam National University, Hanoi, Vietnam

${ }^{6}$ Department of Public Health, Kanazawa Medical University, 1-1 Daigaku, Uchinada, Ishikawa, Japan

${ }^{7}$ Environment Administration, Ministry of Natural Resources and Environment, No. 67 Nguyen Du Street, Hanoi, Vietnam

* Corresponding to : Teruhiko Kido, e-mail; kido@mhs.mp.kanazawa-u.ac.jp, Tel: +81-76-265-2565 Fax:+81-76-234-4363

\section{Acknowledgments}

The authors thank the medical staff at Kim Bang and Phu Cat medical centers for their assistance. We would also like to thank all of the women and their families who participated in the study. Furthermore, we thank the officers of the 10-80 Division, Hanoi Medical University, Vietnam, for making this study possible.

This study was supported by Grant-in-Aid for Scientific Research (A) from the Japan Society for the Promotion of Science (19209021.) and Pfizer Health Research Foundation.

\begin{abstract}
We aimed to determine the relationship between dioxin congeners in maternal breast milk and maternal glucocorticoid levels with newborn birth weight after nearly 45 years of use of herbicides in the Vietnam War. The study subjects comprised 58 mother-infant pairs in a region with high dioxin levels in the soil (hotspot) and 62 pairs from a control region. Dioxin levels in maternal breast milk were measured by HRGC-HRMS. Salivary glucocorticoid levels were determined by LC-MS/MS. Dioxin congener levels in mothers from the hotspot were found to be 2-5-fold higher than those in mothers from the control region. Birth weight was inversely correlated with 2,3,7,8-TeCDD and 2,3,4,7,8-PeCDF congener levels. The rate of newborns whose birth weight was less than $2500 \mathrm{~g}$ was 3 -fold higher in the hotspot $(12 \%)$ than in the control region $(4 \%)$. Salivary glucocorticoid levels in mothers with low birth weight infants were significantly higher than those in the normal birth weight group. Low birth weight of Vietnamese newborns in a hotspot for dioxin levels is related to some dioxin congener levels and high glucocorticoid levels in mothers. This finding in mother-infant pairs suggests that excess maternal glucocorticoid levels are related to dioxin burden and they result in low birth weight.
\end{abstract}

Keywords: Dioxin congener, Dioxin hotspot, Vietnam, Low birth weight, Growth parameter, Glucocorticoid 


\section{INTRODUCTION}

Dioxins are a group of several compounds with similar structures, they greatly vary in toxicity, and are known as polychlorinated dibenzodioxins (PCDDs), polychlorinated dibenzofurans (PCDFs), and polychlorinated biphenyls (PCBs). These compounds of highly toxic dioxin or dioxin-like species are known to be persistent organic pollutants. The compound 2,3,7,8-tetrachlorodibenzo-p-dioxin (TCDD) is one of the most toxic substances found in the environment (Stellman et al. 2003). These compounds enter the human body via the food chain or by respiration and accumulate in fatty tissue, where they have a half-life of 7-11 years because of their lipophilic nature (Milbrath et al. 2009). Dioxins are unwanted by-products of the manufacture of various chlorinated herbicides and pesticides. Dioxins are also released into the atmosphere when polychlorovinyl substances are incinerated. PCBs are a class of chemically stable compounds that were widely used for 50 years in industry as heat-transfer fluids in capacitors and transformers.

However, the situation in Vietnam differs from that described above. Between 1961 and 1971, the US Air Force sprayed over 80 million liters of the defoliant Agent Orange, which is one of several defoliants containing large amounts of a toxic dioxin, and other herbicides over more than $10 \%$ of the surface area of south Vietnam. This spaying was performed to defoliate tropical forests and destroy agricultural production (Stellman et al. 2003).

Similar to many other persistent chemicals that appear in breast milk, dioxin levels decrease with time. The highest levels of TCDD (1832 parts per trillion [ppt]) in breast milk were recorded in 1970 (Schecter et al. 1995) and declined to 11-20 ppt in samples collected from 2000 subjects during 1985-1988. This significant decrease in dioxin levels in the soil in sprayed regions is due to the effects of tropical rain, erosion, and chemical breakdown over the past 45 years. However, considerably higher levels of dioxins associated with Agent Orange use have been observed in the soil around former US airbases in Bien Hoa, Phu Cat, and Da Nang, which are known as hotspots (Dwernychuk, 2005).

We have reported that dioxin levels in blood or breast milk from hotspot residents are 3-5-fold higher than those in a control region in North Vietnam (Kido et al. 2014, Manh et al. 2014, Sun et al. 2014). A similar study in Seveso (Italy) showed TCDD levels in females to be 5 -fold higher in an exposed region than in a control region after 30 years (Mocarelli et al. 2008). The results of residential research suggest that dioxins cause adverse effects on human health by increasing cancer, reproductive problems, immunodeficiency, and endocrine disruption.

Recently, low doses of dioxins and PCBs have been recognized as having adverse effects on human endocrine and neurogenic health. There are several reports concerning the adverse health effects of dioxins, such as neurodevelopmental dysfunction, thyroid deficiency, immunodeficiency, and growth retardation in fetuses (Brouwer et al. 1999, Rogan \&Ragan 2007, Schantz et al. 2003). These chemical toxics, which include polychlorinated dibenzo-pdioxins, dibenzofurans, and PCBs, affect children's growth as a result of prenatal or postnatal exposure (Wang et al. 2004). Pregnant and nursing women may pass the dioxins and/or PCBs to their newborns via transplacental transfer and by breastfeeding mothers (Suzuki et al. 2005, Wang et al. 2004). Several studies on exposure to lower levels of dioxins or PCBs during pregnancy have shown a relationship with low birth weight and other growth parameters (HertzPicciotto et al. 2005, Patandin et al. 1998, Sonneborn et al. 2008).

However, in hotspot areas in Vietnam, the effect of low-level exposure to dioxins on birth size and growth of newborns has received little attention. Therefore, this study aimed to evaluate the effect of low dose levels of dioxin on birth weight and growth parameters of Vietnamese newborns in a hotspot and in an unexposed region. In addition, we investigated the correlation between individual congeneric dioxin levels in maternal breast milk and birth weight to identify the harmful congeners. Furthermore, we analyzed the relation between maternal glucocorticoid levels and low birth weight of newborns as a marker for an adverse intrauterine environment. 


\section{MATERIALS AND METHODS \\ Study region}

- $\quad$ Agent Orange/dioxin hotspot

The research areas in this study were in or around Phu Cat airbase. This area was selected as a dioxin hotspot because it currently has the highest concentration of TCDD in the soil. This is one of three dioxin hotspots in South Vietnam where chemical herbicides were stored and spilled, and where aircrafts that sprayed Agent Orange/dioxin were washed, during the Vietnam War (Dwernychuk 2005).

- Control region

The comparison site was a reference region in Kim Bang district, located in Ha Nam province in north Vietnam. This site was not exposed to chemical defoliants during the war, which is why it was selected as the control region. The hotspot and control region are rural and have not been affected by industrial pollution.

\section{Population}

The study subjects consisted of 58 mother-infant pairs from the dioxin hotspot and 62 pairs from the control region. The age of lactating mothers was between 20 and 30 years, with infants aged between 7 and 16 weeks at the time of sampling. All lactating mothers were asked to complete a health status questionnaire to collect information concerning their family, age, family income, and residence period.

The body mass index (BMI) for lactating mothers and growth parameters (height, weight, and head and chest circumference) for their newborns were determined by medical staff. Breast milk $(20 \mathrm{ml})$ and saliva samples $(2-3$ $\mathrm{ml}$ ) were collected from lactating women from both regions in September 2008 by medical staff. Saliva samples were collected from the hotspot $(n=41)$ and the non-exposed area $(n=36)$ between 08:00 and 10:00 am. We did not collect saliva from lactating mothers who had samples collected in the afternoon since hormone levels were higher in the morning than in the afternoon.. These samples were stored in chemically cleaned cooling containers and frozen on dry ice for several days. They were then transported to Japan and stored at $-30^{\circ} \mathrm{C}$ until analysis.

The temperature in both regions was approximately $30-34^{\circ} \mathrm{C}$ at the time of study. After local government officials and medical staff had explained the purpose of the study to 120 lactating women (58 from the dioxin hotspot and 62 from the control region), they all agreed to participate.

\section{Analysis of dioxin in breast milk}

In this study, dioxin was defined as only PCDDs/PCDFs, not including PCBs. Breast milk samples were analyzed according to a previously reported method (Tai et al. 2011). After extraction of fat from $10 \mathrm{~g}$ of breast milk, $40-80$ pg of $17{ }^{13} \mathrm{C}_{12}$-labeled PCDD/PCDF congeners were added as an internal standard.

A series of purification steps involving alkali digestion and chromatography on a multi-layer silica gel column and an active carbon-dispersed silica gel column were applied to separate and collect the PCDDs/PCDFs. The final sample extract was dried under nitrogen steam and then re-dissolved by adding $20 \mathrm{ml}$ of nonane containing $40 \mathrm{pg}$ of ${ }^{13} \mathrm{C}_{12}$-1,2,3,4-TCDD and ${ }^{13} \mathrm{C}_{12}-1,2,7,8-\mathrm{TCDF}$ as external standards. Finally, dioxin/furan/fractions were determined using high resolution mass spectrometry (MS station-JMS-700; JEOL, Tokyo, Japan) coupled with gas chromatography (HP-6980; Hewlett-Packard, Palo Alto, CA, USA).

Dioxin analysis was carried out in a selected ion monitoring mode at a resolution of 10,000, and the obtained values were converted into toxic equivalents (TEQs) using the World Health Organization toxicity equivalency factors (Van den Berg et al. 2006). Quality control and quality assurance were ensured following the guidelines described in the Japanese Industrial Standard. Eligibilities for the analysis of dioxin were certified using the natural reference powder milk CRM607, which was provided by the European Commission. 
The recovery rate was typically in the range of 60-95\%, and the detection limits were determined at a signal-tonoise ratio of 3 on a lipid basis. Congener levels below the limits of detection were set to $50 \%$ of these limits.

Analysis of salivary steroids by LC-MS/MS

The analytical procedure for the salivary glucocorticoid hormone assay using LC-MS/MS was as reported previously in detail (Kido et al. 2014).

\section{Estimation of the daily dioxin intake of infants from breast milk}

The daily dioxin intake (DDI) was estimated as per previous publications by assuming that the infant (0-24 weeks) consumes $800 \mathrm{ml}$ of milk per day (Schecter et al. 2001, Tai et al. 2011) and taking the weight of the infant at the time into account. The intake value was calculated using the following equation:

DDI $=800 \times(\%$ fat content of milk/100 $) \times($ PCDD $/$ PCDF TEQ in breast milk in $\mathrm{pg} / \mathrm{g}$ lipid $) /(\mathrm{kg}$ of infant weight $)$.

\section{Statistical analyses}

The data are shown as mean and standard deviation (SD) for normal and non-normal distribution, as determined using the Shapiro-Wilk test. Student's t-test was used in the case of normal distribution, and the chi-squared test was used to compare two groups according to continuous or categorical variables. The Mann-Whitney U or KruskalWallis tests were used in the case of non-normal distribution to compare two or more than two groups, respectively. Pearson's correlation coefficients were calculated. The significance level was set at $\mathrm{P}<0.05$. All statistical analyses were carried out using SPSS 12.0 software and Microsoft Excel 2010.

\section{Ethics}

The Medical Ethics Committee of Kanazawa University approved this study. The permission number was Health 89 in 2008. All lactating mothers provided written informed consent.

\section{RESULTS}

Comparison of dioxin congener levels in breast milk of lactating mothers from the dioxin hotspot and unexposed region

The demographic characteristics of the mothers were not significantly different between the dioxin hotspot and the unexposed region in Vietnam, including mean values for residency, age, weight, height, BMI, and family income.

The TEQs of dioxin congener levels in the milk of lactating mothers in the hotspot and unexposed region are shown in Table 1. The levels of most dioxin congeners were significantly higher in the hotspot than in the unexposed region $(\mathrm{p}<0.001)$. The TEQ level of the most toxic congener, 2,3,7,8-TeCDD, was 3.3-fold higher in the hotspot than in the unexposed region. There was no significant difference in the TEQ of 2,3,7,8-TeCDF levels between the two regions. In addition, the TEQ of PCDD levels, TEQ of PCDF levels, and total TEQ of PCDD/PCDF levels in the breast milk of primiparae were significantly higher than those in multiparae.

\section{Comparison of body size and DDI in infants from the hotspot and unexposed region}

Comparison of the size of infants and DDI are shown in Table 2. The DDI from breast milk was 3-4-fold higher in the hotspot than in the unexposed region for infants aged 8-9 or 12-14 weeks. However, there were no significant differences in growth parameters (height, weight, head and chest circumference) between the hotspot and unexposed region.

Correlations between dioxin congener levels in maternal breast milk and birth weight or infant size in the hotspot and unexposed region

The rate of newborns with low birth weight $(<2500 \mathrm{~g})$ was higher in the hotspot $(\mathrm{n}=6,12.0 \%)$ than in the unexposed region $(n=2,4.0 \%)$. 
The correlations between dioxin congeners and birth weight are shown in Table 3. The TEQs of 2,3,7,8TeCDD and 2,3,4,7,8-PeCDF levels showed a significant negative correlation with birth weight (Fig. 1). After birth, there was no significant correlation between infant size and dioxin isomer levels at either 8-9 or 12-14 weeks.

\section{Comparison of salivary glucocorticoid levels and total TEQ of dioxin levels in breast milk of lactating mothers}

Table 4 shows the dioxin levels in maternal breast milk and salivary cortisol and cortisone levels from lactating mothers $(n=78)$ for the three subgroups based on their birth weight of babies. Salivary cortisol and cortisone levels in lactating mothers were significantly higher in the group of low birth weight infants $(<2500 \mathrm{~g})$ than in the normal weight group ( $>2800 \mathrm{~g})$. Although the 2,3,7,8-TeCDD, TEQ 2,3,4,7,8-PeCDF and Total TEQ PCDD/Fs were higher in the group of low birth weight infants $(<2500 \mathrm{~g})$, the statistic were not significant. The reason for the statistic was not significant might be due to large difference in the number of low birth weight infant (3) and the number of normal birth weight infants (66).

\section{DISCUSSION}

Although the end of Operation Ranch Hand was 45 years ago, dioxin residue levels are still high in the soil and in the local residents. This study is important for assessing adverse effects on human health due to dioxin exposure in the second and third generations of the Vietnamese population after the war. We studied a dioxin hotspot and an unexposed region to evaluate the effect of dioxin congeners on growth parameters of Vietnamese newborns in a hotspot. Our study showed that almost 17 dioxin congeners in maternal breast milk (see Table 1) in the hotspot were higher than those in the unexposed region, and some congeners were related to low weight birth. We also evaluated the relation between maternal corticoids levels and low birth weight.

Recent studies have shown that levels of dioxin in humans are 3-5-fold higher in hotspots than in unexposed regions (Kido et al. 2014, Manh et al. 2014). Mothers who are exposed to dioxins could potentially expose their offspring to dioxin during pregnancy as a result of circulation of maternal blood through the placenta (Suzuki et al. 2005). A previous report estimated that an infant who is breastfed for 1 year accumulates a dose of dioxin that is 6-fold higher than that in an infant who is not breastfed (Lorber \& Phillips 2002). Our study showed that DDI from breast milk in infants was approximately 3-4-fold higher in the hotspot than in the unexposed region at 8-9 weeks, decreasing to 3fold at 12-14 weeks (Tables 1 and 2). Hue et al. (2014) studied a different hotspot (Da Nang) to our study and also showed a higher average DDI from breast milk than in the corresponding control region.

There have been several studies on dioxins and their adverse effects on human health, especially during the prenatal and early postnatal periods. The effects of maternal exposure to dioxins on the infant may not manifest themselves immediately and could affect developing organs and lead to disease onset later in life (Konishi et al. 2009, Tai et al. 2011). Our study showed that the rate of low birth weight infants $(<2500 \mathrm{~g})$ was 3 -fold higher in the hotspot than in the unexposed region. Overall, our findings are in agreement with the report by Taylor et al. (1984) on the number of risk factors for infants born with low birth weight. These authors also reported an increased rate of low birth weight infants and shortened gestational age among women who were occupationally exposed to toxic chemicals, such as TCDD or PCBs (Taylor et al. 1989). Similarly, an epidemiological study that aimed to identify dioxin congeners that cause low fetal birth weight reported that 2,3,4,7,8-PeCDF was mainly responsible for this effect (Konishi et al. 2009). Our study showed that two of the 17 dioxin congeners studied in maternal breast milk, namely 2,3,7,8TeCDD and 2,3,4,7,8-PeCDF, reduced birth weight (Table 3 and Fig. 1). This is the first such finding regarding the relationship between the frequency of low birth weight and dioxin congeners in Vietnam.

The mechanism by which dioxins induce low birth weight in pregnancy remains unknown. We found that salivary cortisol and cortisone levels in lactating mothers in the low birth weight group $(<2500 \mathrm{~g})$ were significantly 
higher than those in the normal weight group ( $>2800 \mathrm{~g})$. Based on our findings, we propose a mechanism whereby exposure to excess glucocorticoids inhibits fetal development, with cortisol likely causing low fetal birth weight. We previously reported that glucocorticoid levels in lactating mothers from a hotspot region were higher than those from non-exposed regions, with a strong correlation between glucocorticoids (cortisol and cortisone) and dioxin levels in maternal breast milk (Kido et al. 2014). Several reports have shown that fetal growth is retarded by excess glucocorticoids or pharmacological doses of dexamethasone (Goedhart et al. 2010, Hauser et al. 2007, Koppe et al. 1977, Thorp et al. 2002). Furthermore, a recent study in rats demonstrated that fetuses that were overexposed to high levels of maternal glucocorticoids had intrauterine growth retardation (Kou et al. 2014). However, little is known about the levels of cortisol and how they may affect fetal and postnatal growth.

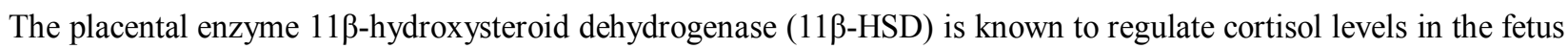
to protect against excess maternal cortisol (Welberg et al. 2000). This enzyme has two forms of $11 \beta$-HSD types 1 and 2 . The role of type $2(11 \beta-H S D 2)$ is to oxidize biologically active cortisol into inactive cortisone (Murphy et al. 1974). In humans, lower placental 11ß-HSD2 activity is correlated with lower birth weight, and infants homozygous for deleterious mutations of the 11ß-HSD2 gene have a lower birth weight (Reynolds 2013). Exposure of the developing fetus to excess cortisol leads to fetal hypothalamic-pituitary-adrenal axis activation, which is associated with low birth weight and long-term adverse outcomes, including metabolic and brain sequelae (Moisiadis \& Matthews 2014). Another action of $11 \beta$-HSD may be to protect cartilage against extensive cortisol action, even in the presence of high cortisol levels. These results indicate that cortisol and its related activating enzyme contribute to the development of catabolism.

In our study, although the DDI from breast milk at 12-14 weeks or longer was higher in the hotspot than in the unexposed area (Table 2), infant body size was not affected (Table 3). This finding suggests that, although low dioxin levels do not continue to affect body size (weight, height, head or chest circumference) of children after birth, they may affect metabolism in children as a result of endocrine disruption. Further research focusing on pediatric endocrinology is necessary to determine any possible adverse health effects of dioxin. 


\section{References}

Beck H, Dross A, Mathar W (1994): PCDD and PCDF exposure and levels in humans in Germany. Environmental health perspectives 102 Suppl 1, 173-85

Brouwer A, Longnecker MP, Birnbaum LS, Cogliano J, Kostyniak P, Moore J, Schantz S, Winneke G (1999): Characterization of potential endocrine-related health effects at low-dose levels of exposure to PCBs. Environmental health perspectives 107 Suppl 4, 639-49

Dwernychuk LW (2005): Dioxin hot spots in Vietnam. Chemosphere 60, 998-9

Fingerhut MA, Sweeney MH, Patterson DG, Piacitelli LA, Morris JA, Marlow DA, Hornung RW, Cameron LW, Connally LB, Needham LL, al e (1989): Levels of 2,3,7,8-tetrachlorodibenzo-p-dioxin in the serum of U.S. chemical workers exposed to dioxin contaminated products: Interim results. Chemosphere 19, 835-840

Goedhart G, Vrijkotte TG, Roseboom TJ, van der Wal MF, Cuijpers P, Bonsel GJ (2010): Maternal cortisol and offspring birthweight: results from a large prospective cohort study. Psychoneuroendocrinology 35, 644-52

Hauser J, Dettling-Artho A, Pilloud S, Maier C, Knapman A, Feldon J, Pryce CR (2007): Effects of prenatal dexamethasone treatment on postnatal physical, endocrine, and social development in the common marmoset monkey. Endocrinology 148, 1813-22

Hertz-Picciotto I, Charles MJ, James RA, Keller JA, Willman E, Teplin S (2005): In utero polychlorinated biphenyl exposures in relation to fetal and early childhood growth. Epidemiology 16, 648-56

Hue NT, Nam VD, Thuong NV, Huyen NT, Phuong NT, Hung NX, Tuan NH, Son LK, Minh NH (2014): Determination of PCDD/Fs in breast milk of women living in the vicinities of Da Nang Agent Orange hot spot (Vietnam) and estimation of the infant's daily intake. The Science of the total environment 491-492, 212-8

Kido T, Dao TV, Ho MD, Duc Dang N, Pham NT, Okamoto R, Pham TT, Maruzeni S, Nishijo M, Nakagawa H, Honma S, Le SK, Nguyen HN (2014): High cortisol and cortisone levels are associated with breast milk dioxin concentrations in Vietnamese women. European journal of endocrinology / European Federation of Endocrine Societies 170, 131-9

Konishi K, Sasaki S, Kato S, Ban S, Washino N, Kajiwara J, Todaka T, Hirakawa H, Hori T, Yasutake D, Kishi R (2009): Prenatal exposure to PCDDs/PCDFs and dioxin-like PCBs in relation to birth weight. Environ Res $109,906-13$

Koppe JG, Smolders-de Haas H, Kloosterman GJ (1977): Effects of glucocorticoids during pregnancy on the outcome of the children directly after birth and in the long run. European journal of obstetrics, gynecology, and reproductive biology 7, 293-9

Kou H, Liu Y, Liang G, Huang J, Hu J, Yan YE, Li X, Yu H, He X, Zhang B, Zhang Y, Feng J, Wang H (2014): Maternal glucocorticoid elevation and associated blood metabonome changes might be involved in metabolic programming of intrauterine growth retardation in rats exposed to caffeine prenatally. Toxicol Appl Pharmacol 275, 79-87

Lorber M, Phillips L (2002): Infant exposure to dioxin-like compounds in breast milk. Environmental health perspectives 110, A325-32

Manh HD, Kido T, Okamoto R, Xianliang S, Anh le T, Supratman S, Maruzeni S, Nishijo M, Nakagawa H, Honma S, Nakano T, Takasuga T, Nhu DD, Hung NN, Son le K (2014): Serum Dioxin Levels in Vietnamese Men more than 40 Years after Herbicide Spraying. Environmental science \& technology 48, 3496-503

Milbrath MO, Wenger Y, Chang CW, Emond C, Garabrant D, Gillespie BW, Jolliet O (2009): Apparent half-lives of dioxins, furans, and polychlorinated biphenyls as a function of age, body fat, smoking status, and breastfeeding. Environmental health perspectives 117, 417-25

Mocarelli P, Gerthoux PM, Patterson DG, Jr., Milani S, Limonta G, Bertona M, Signorini S, Tramacere P, Colombo L, Crespi C, Brambilla P, Sarto C, Carreri V, Sampson EJ, Turner WE, Needham LL (2008): Dioxin exposure, from infancy through puberty, produces endocrine disruption and affects human semen quality. Environmental health perspectives 116, 70-7

Moisiadis VG, Matthews SG (2014): Glucocorticoids and fetal programming part 1: Outcomes. Nature reviews. Endocrinology 10, 391-411

Murphy BE, Clark SJ, Donald IR, Pinsky M, Vedady D (1974): Conversion of maternal cortisol to cortisone during placental transfer to the human fetus. American journal of obstetrics and gynecology 118, 538-41

Patandin S, Koopman-Esseboom C, de Ridder MA, Weisglas-Kuperus N, Sauer PJ (1998): Effects of environmental exposure to polychlorinated biphenyls and dioxins on birth size and growth in Dutch children. Pediatr Res $44,538-45$

Reynolds RM (2013): Glucocorticoid excess and the developmental origins of disease: two decades of testing the hypothesis--2012 Curt Richter Award Winner. Psychoneuroendocrinology 38, 1-11

Rogan WJ, Ragan NB (2007): Some evidence of effects of environmental chemicals on the endocrine system in children. Int J Hyg Environ Health 210, 659-67

Schantz SL, Widholm JJ, Rice DC (2003): Effects of PCB exposure on neuropsychological function in children. Environmental health perspectives 111, 357-576

Schecter A, Furst P, Furst C, Papke O, Ball M, Dai L, Quynh H, Phoung N, Beim A, Vlasov B, Chongchet V, Constable J, Charles K (1991): Dioxins, dibenzofurans and selected chlorinated organic compounds in 
humanmilk and blood from Cambodia, Germany, Thailand, The USA, the USSR, and Vietnam. Chemosphere 23, 1903-1912

Schecter A, Dai LC, Thuy LT, Quynh HT, Minh DQ, Cau HD, Phiet PH, Nguyen NT, Constable JD, Baughman R, et al. (1995): Agent Orange and the Vietnamese: the persistence of elevated dioxin levels in human tissues. Am J Public Health 85, 516-22

Schecter A, Cramer P, Boggess K, Stanley J, Papke O, Olson J, Silver A, Schmitz M (2001): Intake of dioxins and related compounds from food in the U.S. population. Journal of toxicology and environmental health. Part A 63, $1-18$

Sonneborn D, Park HY, Petrik J, Kocan A, Palkovicova L, Trnovec T, Nguyen D, Hertz-Picciotto I (2008): Prenatal polychlorinated biphenyl exposures in eastern Slovakia modify effects of social factors on birthweight. Paediatr Perinat Epidemiol 22, 202-13

Stellman JM, Stellman SD, Christian R, Weber T, Tomasallo C (2003): The extent and patterns of usage of Agent Orange and other herbicides in Vietnam. Nature 422, 681-7

Sun XL, Kido T, Okamoto R, Manh HD, Maruzeni S, Nishijo M, Nakagawa H, Honma S, Nakano T, Takasuga T, Nhu DD, Hung NN, Son le K (2014): Relationship between dioxin and steroid hormones in sera of Vietnamese men. Biomarkers : biochemical indicators of exposure, response, and susceptibility to chemicals $19,236-40$

Suzuki G, Nakano M, Nakano S (2005): Distribution of PCDDs/PCDFs and Co-PCBs in human maternal blood, cord blood, placenta, milk, and adipose tissue: dioxins showing high toxic equivalency factor accumulate in the placenta. Biosci Biotechnol Biochem 69, 1836-47

Tai PT, Nishijo M, Kido T, Nakagawa H, Maruzeni S, Naganuma R, Anh NT, Morikawa Y, Luong HV, Anh TH, Hung NN, Son le K, Tawara K, Nishijo H (2011): Dioxin concentrations in breast milk of Vietnamese nursing mothers: a survey four decades after the herbicide spraying. Environmental science \& technology 45, 6625-32

Taylor PR, Lawrence CE, Hwang HL, Paulson AS (1984): Polychlorinated biphenyls: influence on birthweight and gestation. American journal of public health 74, 1153-4

Taylor PR, Stelma JM, Lawrence CE (1989): The relation of polychlorinated biphenyls to birth weight and gestational age in the offspring of occupationally exposed mothers. American journal of epidemiology 129, 395-406

Thorp JA, Jones PG, Knox E, Clark RH (2002): Does antenatal corticosteroid therapy affect birth weight and head circumference? Obstetrics and gynecology 99, 101-8

Van den Berg M, Birnbaum L, Denison M, De Vito M, Farland W, Feeley M, Fiedler H, Hakansson H, Hanberg A, al. HL (2006): The (2005) World Health Organization re-evaluation of human and mammalian toxic equivalency factors for dioxins and dioxin-like compounds. Toxicological Sciences 93, 223-241

Wang SL, Lin CY, Guo YL, Lin LY, Chou WL, Chang LW (2004): Infant exposure to polychlorinated dibenzo-pdioxins, dibenzofurans and biphenyls (PCDD/Fs, PCBs)--correlation between prenatal and postnatal exposure. Chemosphere 54, 1459-73

Welberg LA, Seckl JR, Holmes MC (2000): Inhibition of 11beta-hydroxysteroid dehydrogenase, the foeto-placental barrier to maternal glucocorticoids, permanently programs amygdala GR mRNA expression and anxietylike behaviour in the offspring. The European journal of neuroscience 12, 1047-54 
Table 1. Dioxin isomer levels in maternal breast milk in the hotspot and control region

\begin{tabular}{|c|c|c|c|c|c|c|c|c|c|}
\hline & \multirow{2}{*}{$\begin{array}{l}\text { Dioxin Isomers } \\
\text { (pg/g of lipid) }\end{array}$} & \multicolumn{3}{|c|}{ Control region } & \multicolumn{3}{|c|}{ Hotspot region } & \multirow[b]{2}{*}{$\mathrm{H} / \mathrm{Ca}^{\mathrm{a}}$} & \multirow[b]{2}{*}{$p$ value $e^{b}$} \\
\hline & & $\mathrm{N}$ & Mean & SD & $\mathrm{N}$ & Mean & SD & & \\
\hline \multirow[t]{7}{*}{ PCDDs } & TEQ "2,3,7,8-TeCDD" & 62 & 0.458 & 0.345 & 58 & 1.514 & 0.712 & 3.3 & $* * *$ \\
\hline & TEQ “1,2,3,7,8-PeCDD” & 62 & 1.314 & 0.594 & 58 & 4.434 & 1.816 & 3.4 & $* * *$ \\
\hline & TEQ "1,2,3,4,7,8-HxCDD" & 62 & 0.065 & 0.026 & 58 & 0.209 & 0.085 & 3.2 & $* * *$ \\
\hline & TEQ "1,2,3,6,7,8-HxCDD" & 62 & 0.138 & 0.061 & 58 & 0.741 & 0.349 & 5.4 & $* * *$ \\
\hline & TEQ "1,2,3,7,8,9-HxCDD" & 62 & 0.061 & 0.026 & 58 & 0.281 & 0.118 & 4.7 & $* * *$ \\
\hline & TEQ "1,2,3,4,6,7,8-HpCDD" & 62 & 0.025 & 0.009 & 58 & 0.141 & 0.062 & 5.7 & $* * *$ \\
\hline & TEQ “OCDD” & 62 & 0.004 & 0.002 & 58 & 0.021 & 0.009 & 5.9 & $* * *$ \\
\hline \multirow[t]{10}{*}{ PCDFs } & TEQ "2,3,7,8-TeCDF" & 62 & 0.067 & 0.029 & 58 & 0.070 & 0.033 & 1.1 & \\
\hline & TEQ "1,2,3,7,8-PeCDF" & 62 & 0.014 & 0.008 & 58 & 0.065 & 0.037 & 4.6 & $* * *$ \\
\hline & TEQ "2,3,4,7,8-PeCDF" & 62 & 0.914 & 0.333 & 58 & 1.909 & 0.716 & 2.1 & $* * *$ \\
\hline & TEQ "1,2,3,4,7,8-HxCDF" & 62 & 0.196 & 0.072 & 58 & 1.592 & 0.845 & 8.1 & $* * *$ \\
\hline & TEQ "1,2,3,6,7,8-HxCDF" & 62 & 0.166 & 0.062 & 58 & 0.926 & 0.451 & 5.6 & $* * *$ \\
\hline & TEQ "1,2,3,7,8,9-HxCDF" & 62 & 0.014 & 0.008 & 58 & 0.041 & 0.029 & 2.9 & $* * *$ \\
\hline & TEQ "2,3,4,6,7,8-HxCDF" & 62 & 0.055 & 0.029 & 58 & 0.159 & 0.063 & 2.9 & $* * *$ \\
\hline & TEQ "1,2,3,4,6,7,8-HpCDF" & 62 & 0.015 & 0.008 & 58 & 0.183 & 0.120 & 12.4 & $* * *$ \\
\hline & TEQ "1,2,3,4,7,8,9-HpCDF" & 62 & 0.002 & 0.001 & 58 & 0.018 & 0.012 & 9.9 & $* * *$ \\
\hline & TEQ “OCDF" & 62 & 0.000 & 0.000 & 58 & 0.001 & 0.001 & 4.8 & $* * *$ \\
\hline \multirow[t]{3}{*}{ Total } & TEQ "Total PCDDs" & 62 & 2.064 & 0.931 & 58 & 7.342 & 2.865 & 3.6 & $* * *$ \\
\hline & TEQ "Total PCDFs" & 62 & 1.442 & 0.482 & 58 & 4.965 & 2.054 & 3.4 & $* * *$ \\
\hline & TEQ "PCDDs + PCDFs" & 62 & 3.506 & 1.354 & 58 & 12.307 & 4.431 & 3.5 & $* * *$ \\
\hline
\end{tabular}

Data are shown as mean \pm SD and were analyzed using the Mann-Whitney U test.

Toxic equivalent: TEQ (pg/g of lipid).

a Ratios of mean dioxin levels in the hotspot and control region.

$\mathrm{b} * * * \mathrm{p}<0.001$. 
Table 2. Comparison of body size of infants and the DDI in the two age groups from the hotspot and control regions

\begin{tabular}{cllllllll}
\hline \multirow{2}{*}{$\begin{array}{c}\text { Infant } \\
\text { group }\end{array}$} & & \multicolumn{3}{c}{ Control region } & \multicolumn{3}{c}{ Hotspot region } & p value \\
\cline { 2 - 7 } & index & $\mathrm{N}$ & Mean & SD & $\mathrm{N}$ & Mean & SD & \\
\hline $\begin{array}{c}\text { 8-9 } \\
\text { weeks }\end{array}$ & Age (weeks) & 20 & 9.7 & 0.88 & 32 & 9.0 & 1.69 & 0.090 \\
& Height (cm) & 20 & 59.5 & 2.35 & 32 & 59.8 & 3.10 & 0.642 \\
& Weight (g) & 20 & 5433 & 481 & 32 & 5415 & 963 & 0.937 \\
& Head (cm) & 20 & 39.0 & 1.19 & 32 & 39.2 & 1.38 & 0.623 \\
& Chest (cm) & 20 & 40.0 & 1.49 & 32 & 39.6 & 2.60 & 0.543 \\
& DDI (TEQ pg/kg/d) & 20 & 18.0 & 8.97 & 32 & 54.2 & 28.20 & 0.000 \\
weeks 14 & Age (weeks) & 41 & 14.6 & 2.02 & 23 & 13.9 & 1.84 & 0.139 \\
& Height (cm) & 41 & 62.2 & 2.42 & 23 & 62.4 & 2.52 & 0.767 \\
& Weight (g) & 41 & 6277 & 821 & 23 & 6108 & 807 & 0.430 \\
& Head (cm) & 41 & 40.7 & 1.74 & 23 & 40.9 & 1.57 & 0.672 \\
& Chest (cm) & 41 & 41.5 & 2.11 & 23 & 40.9 & 2.39 & 0.312 \\
& DDI (TEQ pg/kg/d) & 41 & 12.3 & 4.93 & 22 & 42.7 & 23.96 & 0.000 \\
\hline
\end{tabular}

DDI: daily dioxin intake.

Data are shown as mean $\pm \mathrm{SD}$.

Statistical significance was tested using Student's t-test. 
Table 3. Correlations between dioxin isomer levels in maternal breast milk and birth weight and infant size

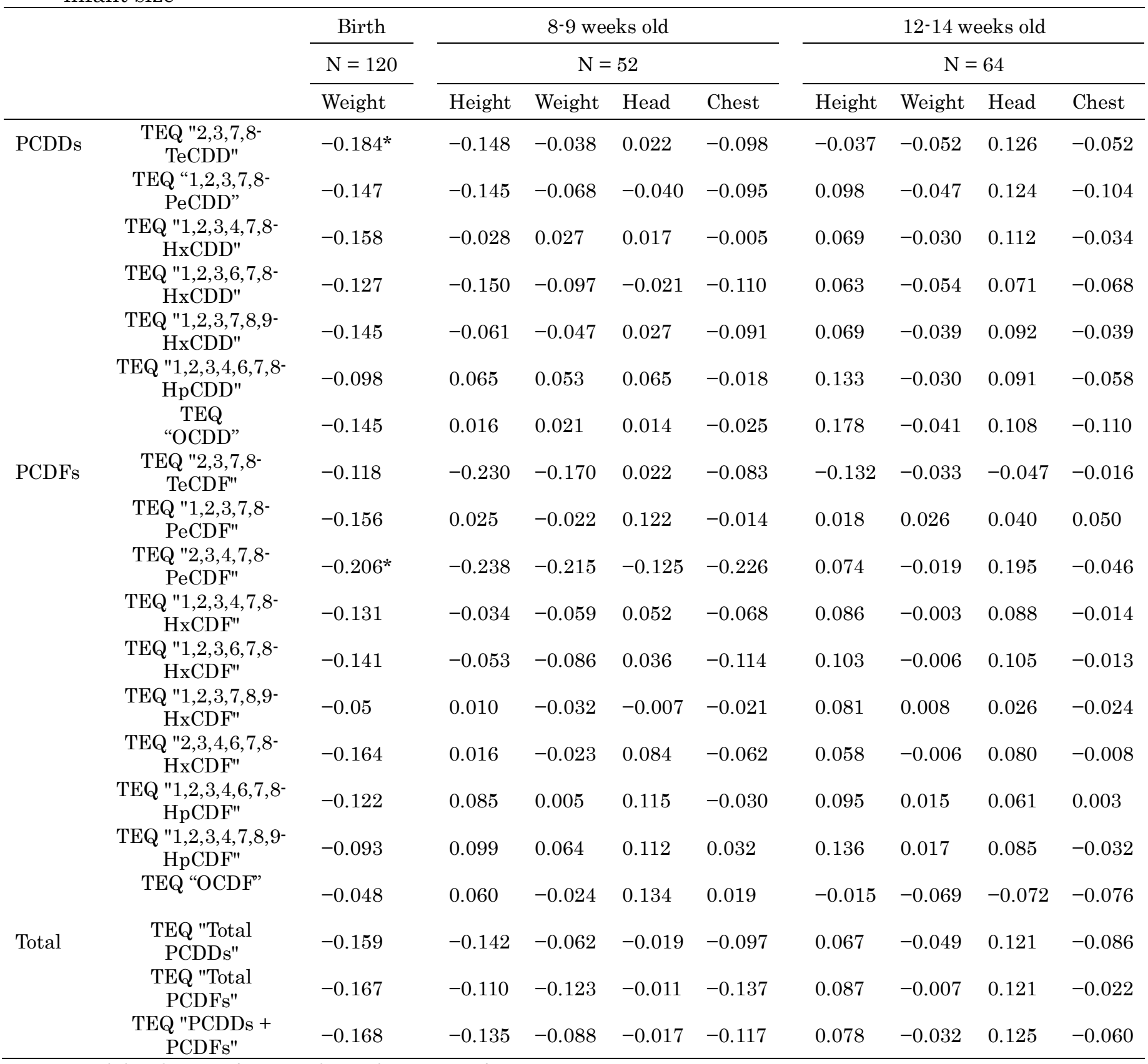

Head: head circumference, chest: chest circumference.

* $p<0.05$ 
Table 4. Salivary glucocorticoid and dioxin levels in breast milk in lactating mothers with division into three groups based on birth weight

\section{Baby group}

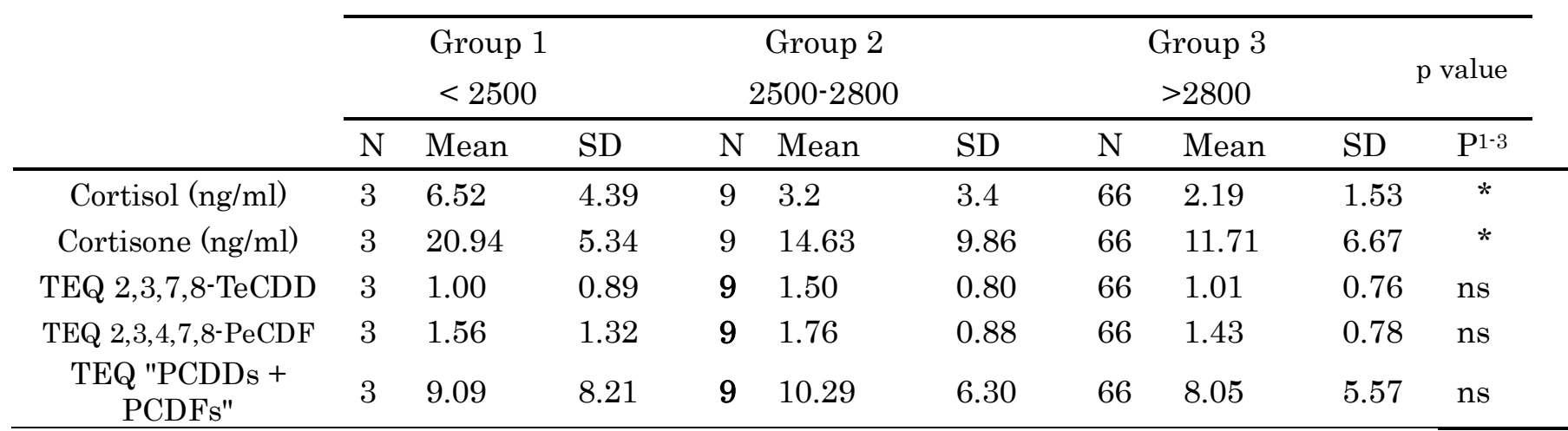

Data are shown as mean $\pm \mathrm{SD}$, and were analyzed using the Kruskal-Wallis test for more than two groups and the Mann-Whitney U test for two groups.

Toxic equivalent: TEQ (pg/g of lipid).

$* \mathrm{p}<0.05$. 

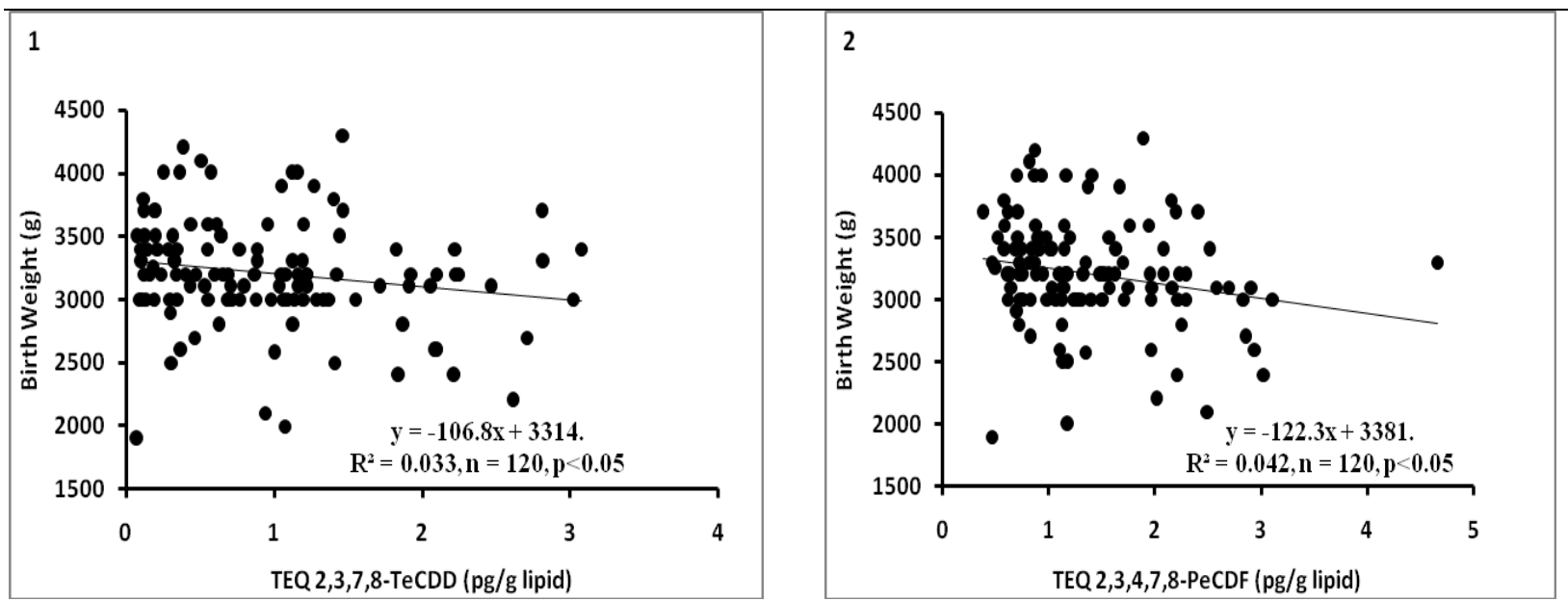

Fig. 1 Correlations between birth weight and dioxin isomers in maternal breast milk. 